\title{
Simultaneous Effects of Dietary Molybdenum and Copper on Key Enzymes of Rat Liver A Histochemical Study
}

\author{
AJAY KUMAR and S.V.S. RANA \\ School of Environmental Contamination \& Toxicology, Department of Zoology, \\ D.A.V. (P.G.) College, Muzaffarnagar-251001, India
}

(Received April 7, 1982)

\begin{abstract}
Molybdenum and copper when administered to animals are known to accumulate predominantly in liver, causing identifiable toxic effects on enzyme systems. Since, molybdenum and copper are known as antagonists, effects of their combined treatment have been described in the present investigation taking enzymes of key importance viz. alkaline phosphatase, acid phosphatase, glucose- 6 phosphatase, 5-nucleotidase, esterases and cholinesterase in the liver of rat, Rattus rattus albino. Comparison of controls with the combined effects revealed an increase in the activity of enzymes studied, however, some remarkable differences in their topography were observed. Antagonistic behaviour of molybdenum and copper at the enzymological level has been explained on the basis that copper becomes unavailable through interaction with molybdate to form either cupric molybdate or copper thiomolybdate which is ultimately excreted. The results have further been interpreted in terms of combined effects of molybdenum and copper on cellular organelle, levels of enzyme protein and microenvironment of the hepatic parenchyma.
\end{abstract}

Keywords: Molybdenum-Copper-Antagonism-Enzymes-Liver

\section{INTRODUCTION}

The essentiality and importance of molybdenum (Mo) and copper $(\mathrm{Cu})$ in animal and human nutrition has long been recognized (Richert and Westerfeld, 1953; Mertz and Cornatzer, 1971; Underwood, 1971) ${ }^{1-3)}$. However, their intake in excess have been found toxic. The pathogenesis of $\mathrm{Mo}$ and $\mathrm{Cu}$ induced toxicity has been studied by several workers (Jeter and Davis, 1954; Dutt and Mills, 1960; Todd, 1969; Evans and Abraham, 1973; Rana and Kumar, 1980a, b) ${ }^{4-9)}$. It is well known that high dietary levels of molybdenum or sulfur can be antagonistic to copper metabolism and may lead to copper deficiency. Arrington and Davis $(1953)^{10)}$ found that supplementation with $\mathrm{Cu}$ prevented the growth depression brought by high Mo intakes in rabbits. However, the first evidence on Mo-Cu 
interaction was observed when the drasting scouring disease of cattle known as "teart" was shown to be a manifestaiton of chronic molybdenum poisoning and could be controlled by treating the cattle with large doses of copper sulfate (Ferguson et al. 1938; 1943) ${ }^{11,12}$. Other reports favouring physiological antagonism are those of Dick $(1954 ; 1956)^{13,14}$. However, their combined effects have not been studied in details. Present study reports on the simultaneous effects of molybdenum and copper on key enzymes viz. alkaline phosphatase, acid phosphatase, glucose-6-phosphatase, 5-nucleotidase, glucose-6-phosphatase, esterases and cholinesterase in the liver of rat, Rattus rattus albino. Rana and Kumar (1980c; $1981)^{15,16)}$ have already shown that molybdenum and copper caused dysenzymia-a major event in the metal toxicity, therefore to confirm further the antagonistic behaviour of molybdenum and copper at the enzymological level present studies were undertaken.

\section{Materials ANd Methods}

Twenty male adult albino rats, Rattus rattus albino, three months old and weighing $100 \pm 10 \mathrm{gm}$ were selected from the laboratory stock. A group of 10 rats were fed orally on a mixture of ammonium molybdate (BDH mol. weight 195.966) and copper sulfate (BDH mol. weight 249.690) in the ratio of $1: 1$ at the total dosage of $2.0 \mathrm{gm} / \mathrm{kg}$ body weight with the laboratory diet (Hindustan Lever Ltd., Bombay) by gavage and tap water ad libitum regularly for 20 days. Another group of 10 rats fed on lab. diet and tap water only served as controls. Each rat was housed separately in a suitable cage under standard laboratory conditions. Total weight of the diet was kept constant throughout the experiment.

After twenty days, all the rats were starved for $24 \mathrm{hr}$ and then sacrificed by decapitation. Small pieces of liver from different lobes and from each rat were fixed in chilled absolute acetone for $24 \mathrm{hr}$ at $4^{\circ} \mathrm{C}$. Paraffin, fixed frozen and fresh frozen sections (as prescribed) were prepared and processed for histochemical localization of alkaline phosphatase (Burstone, 1962) ${ }^{17)}$, acid phosphatase (Gomori, 1941) ${ }^{18)}$, 5-nucleotidase (Pearse and Reis, 1952) ${ }^{19)}$, glucose6-phosphatase (Chiquoine, 1953) ${ }^{20)}$, esterases (Gomori, 1952) ${ }^{21)}$ and cholinesterase (Koelle and Periendenwald, 1949) ${ }^{22}$. Suitable reaction controls were also made simultaneously.

\section{RESUlts}

Topographical changes were observed in the anatomic localization of enzymes in the liver of rats fed simultaneously on molybdenum and copper are as follows:

A uniform reaction for alkaline phosphatase was observed in the entire hepatic parenchyma of control rats (Fig. 1). Administration of molybdenum and copper 

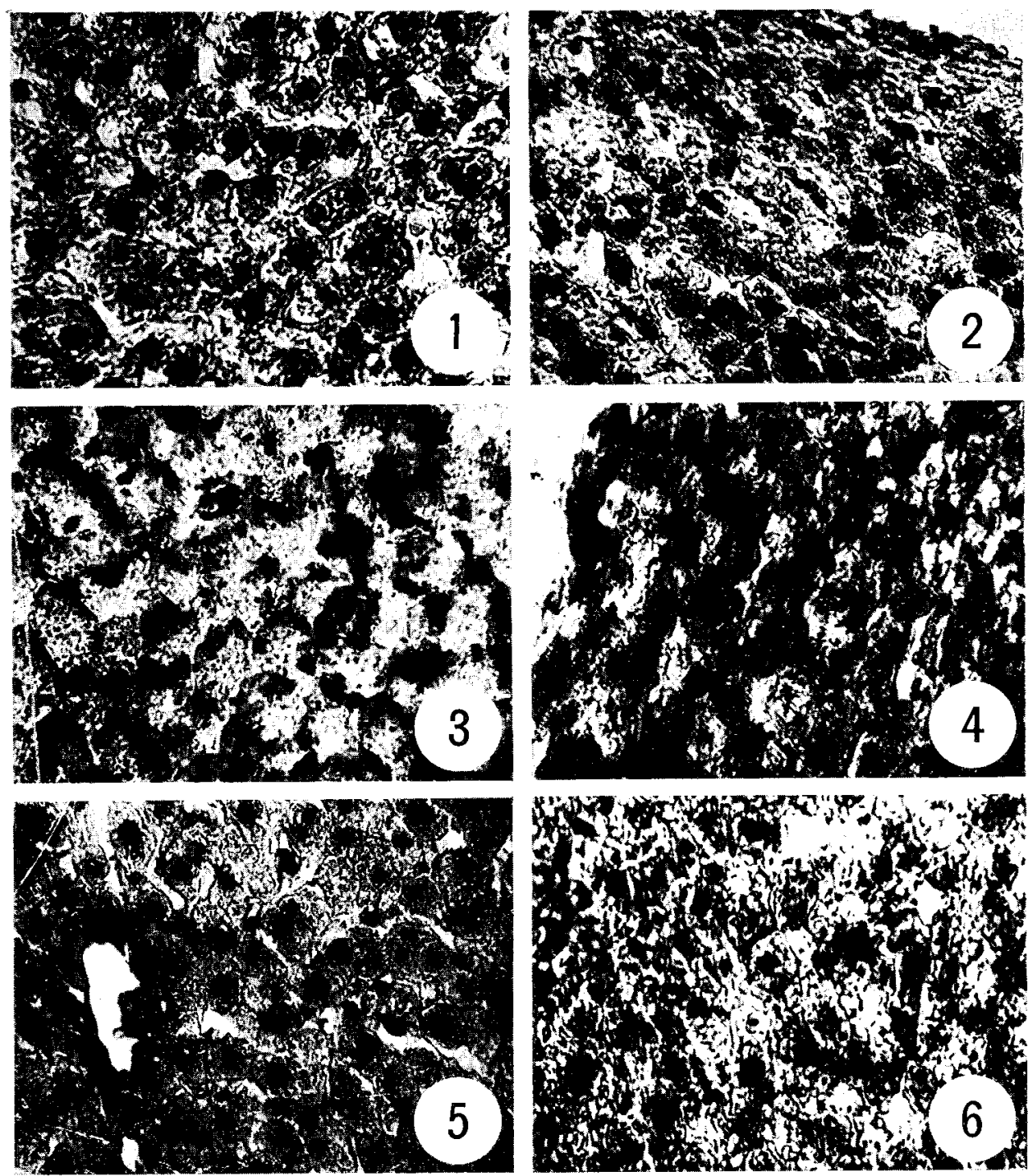

Fig. 1. Liver from a control rat exhibited alkaline phosphatase reaction in the hepatic parenchyma throughout the entire lobule. $\times 320$.

Fig. 2. Stimulation of alkaline phosphatase was found at the perilobular zone in the liver of $\mathrm{Mo}+\mathrm{Cu}$ treated rats. $\times 320$.

Fig. 3. Strong acid phosphatase reaction was exhibited by the parenchymal cells of control liver. $\times 320$.

Fig. 4. After $\mathrm{Mo}+\mathrm{Cu}$ treatment, hepatic parenchyma of the perilobular region showed an intense reaction for acid phosphatase. $\times 320$.

Fig. 5. Uniform reaction for 5 -nucleotidase was observed in a normal liver. $\times 240$.

Fig. 6. Administration of $\mathrm{Mo}$ and $\mathrm{Cu}$ together stimulated 5 -nucleotidase activity throughout the entire lobule. $\times 320$, 

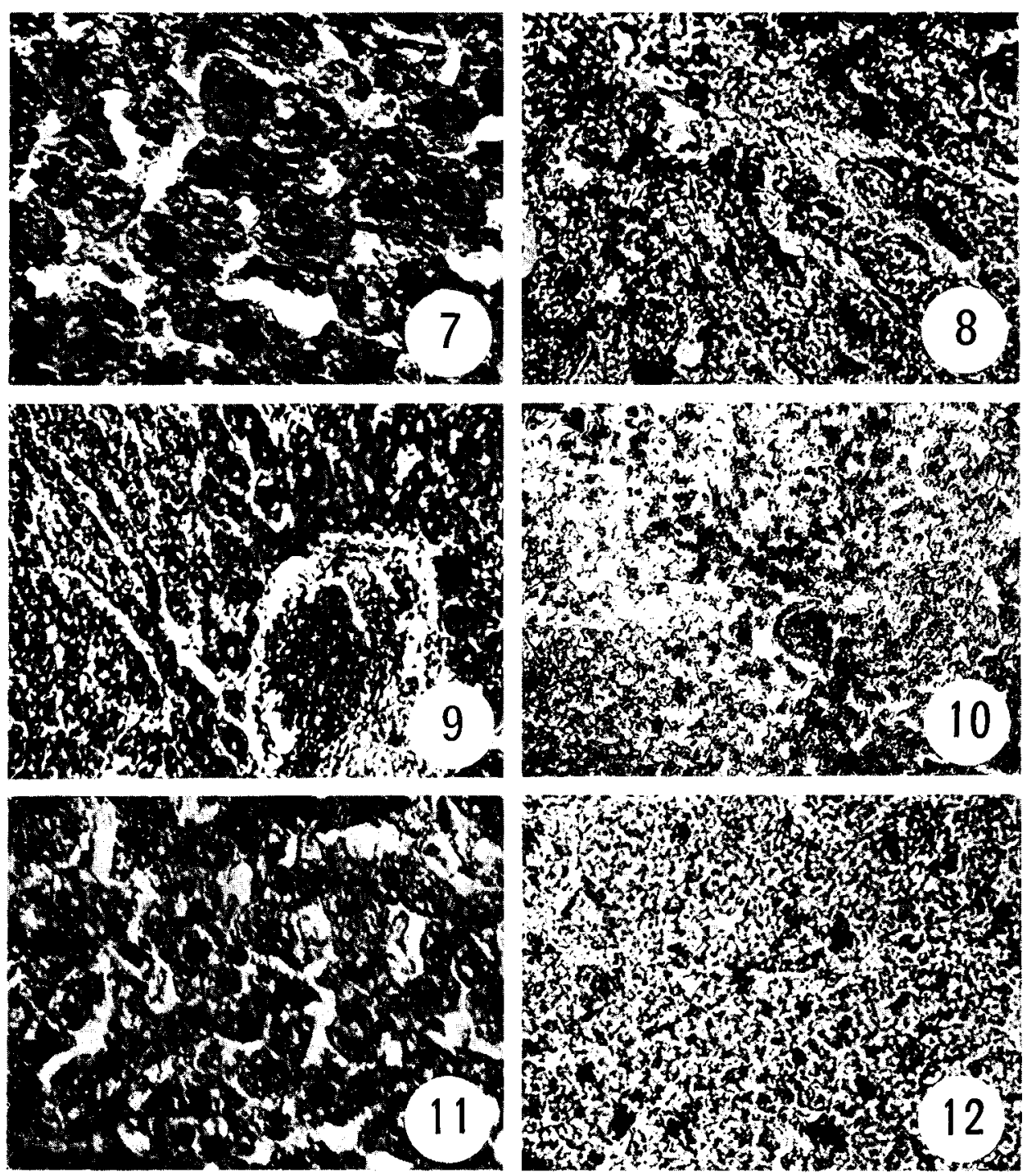

Fig. 7. Fresh frozen sections of liver from a control rat showed glucose-3-phosphatase rich parenchyma. $\times 320$.

Fig. 8. Intermediate zone of the lobule exhibited a strong positive reaction for glucose-6-phosphatase in the liver of $\mathrm{Mo}+\mathrm{Cu}$ fed rats. $\times 320$.

Fig. 9. Centrolobular parenchyma showed a positive reaction for esterases in control rats. $\times 150$.

Fig. 10. In the liver of $\mathrm{Mo}+\mathrm{Cu}$ fed rats, hepatic cells near the central vein exhibited a strong reaction for esterases. $\times 80$.

Fig. 11. A moderate reaction for cholinesterase was visualized in the entire lobule of a control rat. $\times 320$.

Fig. 12. Strong diffused cytoplasmic activity of cholinesterase was observed in the liver of rats ingested with $\mathrm{Mo}$ and $\mathrm{Cu}$ both. $\times 500$, 
Table 1. Combined effects of molybdenum and copper on the localization of enzyme activities in the liver of albino rats.

\begin{tabular}{|c|c|c|c|c|c|c|c|c|}
\hline \multirow{2}{*}{ Enzyme } & \multicolumn{4}{|c|}{ Control liver } & \multicolumn{4}{|c|}{$\mathrm{Mo}+\mathrm{Cu}$ treated liver } \\
\hline & $\mathrm{a}$ & $\mathrm{b}$ & $\mathrm{c}$ & $\mathrm{d}$ & $\mathrm{a}$ & b & $\mathrm{c}$ & $\mathrm{d}$ \\
\hline Alkaline phosphatase & + & + & - & - & + & H & - & - \\
\hline Acid phosphatase & H & H & \pm & - & H & H & - & - \\
\hline 5-nucleotidase & + & + & - & - & H & $H$ & - & \pm \\
\hline Glucose-6-phosphatase & H & H & - & - & $H^{i z}$ & $H^{i z}$ & \pm & \pm \\
\hline Esterase & + & \pm & - & - & H & \pm & \pm & - \\
\hline Cholinesterase & + & + & - & - & $H^{c d}$ & $H^{c d}$ & - & - \\
\hline
\end{tabular}

$\mathrm{a}$ : centrolobular parenchyma; $\mathrm{b}$ : perilobular parenchyma; $\mathrm{c}$ : bile canaliculi ;

$\mathrm{d}$ : sinusoids.

$\mathrm{H}$ : intense activity; $H$ : strong; + : moderate; \pm : dull; $-:$ no activity.

$H^{\mathrm{iz}}$ : strong activity at the intermediary zone.

$H^{\text {ed }}$ : strong cytoplasmic diffused activity.

together, stimulated its activity particularly at the perilobular region (Fig. 2). For acid phosphatase, as usual, a strong reaction was exhibited by the hepatic cells (Fig. 3). Hepatic parenchyma of the perilobular zone showed an intense reaction for acid phosphatase after $\mathrm{Mo}+\mathrm{Cu}$ treatment (Fig. 4). Control liver showed a uniform activity for 5-nucleotidase throughout the liver lobule (Fig. 5). Liver of $\mathrm{Mo}+\mathrm{Cu}$ fed rats exhibited an increase in the activity of 5-nucleotidase throughout the entire lobule (Fig. 6). Normal liver exhibited a strong activity for glucose-6-phosphatase (Fig. 7), whereas, a great stimulation was observed in the parenchymal cells of the intermediary zone after the combined treatment of molybdenum and copper (Fig. 8). Centrolobular parenchyma exhibited a positive reaction for esterase in control rats (Fig. 9). Hepatic cells near the central vein were found rich in esterases after feeding the rats on molybdenum and copper (Fig. 10). A moderate reaction for cholinesterase was found in the liver of control rats throughout the entire lobule (Fig. 11). Strong but diffused cytoplasmic activity of cholinesterase was observed in the liver of $\mathrm{Mo}+\mathrm{Cu}$ treated rats (Fig. 12). Topographical differences on the distribution of these enzymes has been summarized by Table 1 .

\section{Discussion}

Most interesting aspects of $\mathrm{Mo}$ and $\mathrm{Cu}$ are the roles they play in biological processes such as oxidation and reduction of several enzymes. Like other heavy metals they may also block enzymes by inhibiting SH groups and dislodging the chain. Since, biochemical results furnish information of total tissue, regional differences on their topography in liver thus noted by histochemical methods greatly helped in manifesting the combined toxicity if any to liver and establishing the exact localization of functional disturbances. However, Mo and $\mathrm{Cu}$ induced 
hepatic dysenzymia was reported by Rana and Kumar (1980c, 1981) ${ }^{15,16)}$. Present observations showed that in the rats fed simultaneously on $\mathrm{Mo}$ and $\mathrm{Cu}$, no inhibition of liver enzymes invesitgated confirm the biochemical data reported earlier (Rana and Kumar, 1980c $)^{15}$ ). Stimulated reaction of alkaline phosphatase neither indicates injury to plasma membrane nor a change in the transport of pohsphate through it. Perhaps this increase shows adaptation to the changed environment taking place in the plasma membrane, degree of its elevation might be depending on the state of plasma membrane at the time of injury. No lysosomal damage was caused by these elements when administered together as evidenced by a stimulated reaciton for acid phosphatase. Experimental evidences on acid phosphatase showed that it is not restricted to lysosomal fraction but has also been found in golgi cisternae and specialized region of endoplasmic reticulum known as GERL (Farquhar et al., 1974) ${ }^{23)}$. 5-nucleotidase is also located in plasma membrane of most of the cells and is widely used as marker enzyme (De Duve, 1971) ${ }^{24)}$. Increased activity of 5-nucleotidase also showed the favourable effects. Histochemically observed change in the activity of enzyme marking endoplasmic reticulum, i.e. glucose-6phosphatase very probably point to variations in the production of glucose needed by the cell itself or to provide other cells with this source of energy. Isoenzymes studies by Hermes et al. (1975) ${ }^{25)}$ have shown that numerous forms of esterases are present in several tissues. In rat liver different distribution patterns were observed with different substrates by Deimling and Madreiter (1972) ${ }^{26)}$ and Bocking et al. (1975) ${ }^{27)}$. Probably the increased esterase activity noted reflects elevation in phospholipid synthesis. A change in the cholinesterase activity ultimately reflects the effects of $\mathrm{Mo}+\mathrm{Cu}$ on the hydrolysis of acetylcholine to choline and acetic acid and further showed the state of phagocytosis and related phenomenon. Restoration and stimulation of these enzymes after their combined treatment reflects no synergistic effects but favours antagonism and suggest repair in cellular particles and normal metabolic pathways. However, causes explaining these enzymological differences described above further need verification. However, the mchanism behind chemical modification of enzymes might be phosphorylation, adenylation, ADP-ribosylation, oxidation of thiol groups and respective reverse reactions. A change in the balance between synthesis and degradation of the enzyme protein can also be altered by nutritional variables (Schmike and Dehlinger, 1972) ${ }^{28)}$. Presumably the variations in the level of enzyme protein and state of cellular organelle have implications for the interpretation of these changes in enzyme activities.

Majority of enzymes discussed above favour antagonism between molybdenum and copper. Dick (1954) ${ }^{13 !}$ made the original discovery that Mo limits $\mathrm{Cu}$ retention only in the presence of adequate dietary or endogenous sulfate. Mills $(1961)^{29)}$ contended that molybdate and sulfate restrict copper utilization in sheep depressing the solubility of $\mathrm{Cu}$ in the digestive tract through the precipitation of cupric sulfide. A hypothesis recently put forward by Huisingh et al. 
$(1973)^{30)}$ proposes that $\mathrm{Cu}$ becomes unavailable through two routes (i) through the formation of a biologically unavailable $\mathrm{Cu}-\mathrm{Mo}$ complex called cupric molybdate which is absorbed, transported and excreted as a unit making Mo and $\mathrm{Cu}$ both less available and (ii) through the formation of an insoluble cupric sulfide in the rumen, the intestine or other tissues.

Another concept of the formation of a thiomolybdate ion and the tight complexing of this ion with $\mathrm{Cu}$ independently proposed by Suttle (1975) ${ }^{31)}$ represents a significant step forward involving, for the first time a true three way $\mathrm{Cu}-\mathrm{Mo}-\mathrm{S}$ interaction.

Inspite of all the above experimental evidences, an understanding of the mechanism of interaction of Mo with Cut in the presence of endogenous sulfate at the blood, or tissue level has been rather more elusive. It is proposed that copper metabolism is effected by molybdate in the following ways.

1. Mobilization of copper from the liver.

2. Inhibition of copper uptake by the tissues and possibly inhibition of copper transport both in to and out of the liver.

3. Inhibition of the synthesis of copper-storing complexes and ceruiloplasmin.

\section{ACKNOWLEDGEMENT}

Financial assistance by Council of Scientific and Industrial Research, New Delhi is gratefully acknowledged.

\section{REFERENCES}

1) Richert, D.A. and Westerfeld, W.W. (1953). J. Biol. Chem., 203, 915.

2) Mertz, W.E. and Cornatzer, D.W. (1971). In New Trace Elements in Nutrition. Marcel and Dekkar, New York.

3) Underwood, E.J. (1971). In Trace Elements in Human and Animal Nutrition. Acad. Press, New York.

4) Jeter, M. and Davis, G.K. (1954). J. Nutr., 54, 215.

5) Dutt, B. and Mills, C.F. (1960). J. Comp. Pathol. Ther., 70, 120.

6) Todd, J.R. (1969). Proc. Nutr. Sci., 28, 189.

7) Evans, J.L. and Abraham, P.A. (1973). J. Nutr., 103, 196.

8) Rana, S.V.S. and Kumar, A. (1980a). Indust. Health, 18, 9.

9) Rana, S.V.S. and Kumar, A. (1980b). Curr. Sci., 49, 383.

10) Arrington, L.R. and Davis, G.K. (1953). J. Nutr., 51, 295.

11) Ferguson, A.S., Lewis, A.H. and Watson, S.J. (1938). Nature (London), 141, 533.

12) Ferguson, A.S., Lewis, A.H. and Watson, S.J. (1943). Agric. Sci., 33, 44.

13) Dick, A.T. (1954). Aust. J. Agric. Res., 5, 511.

14) Dick, A.T. (1956). Soil. Sci., 81, 229.

15) Rana, S.V.S. and Kumar, A. (1980c). Toxicol. Lett., 6, 163.

16) Rana, S.V.S. and Kumar, A. (1981). Zool. Jb. Anat., 105, 177.

17) Burstone, M.S. (1962). Enzyme histochemistry and its application to the study of Neoplasms. Acad. Press, New York, London.

18) Gomori, G. (1941). Arch. Pathol., 32, 188. 
19) Pearse, A.G.E. and Reis, J.L. (1952). Biochim. J., 50, 534.

20) Chiquoine, A.D. (1953). J. Histochem. Cytochem., 1, 429.

21) Gomori, G. (1952). Internal Rev. Cytol., 1, 335.

22) Koelle, G.B. and Periendenwald, J.S. (1949). Proc. Soc. Exp. Biol. and Med., 70, 617.

23) Farquhar, M.G., Bergeron, J.J.M. and Palade, G.E. (1974). J. Cell. Biol., 60, 8.

24) De Duve, C. (1971). J. Cell. Biol., 50, 20.

25) Hermes, B., Riebschlager, M. and V. Deimling, O. (1975). Histochemistry, 43, 81.

26) V. Deimling, O. and Madrueiter, H. (1972). Histochemie, 29, 83.

27) Bocking, A., Groszarth, C. and V. Deimling, O. (1974). Histochemistry, 42, 359.

28) Schimke, R.T. and Dehlinger, P.J. (1972). In Membrane Research (Fox, C.F., Ed.) p. 115-133, Acad. Press, New York, London.

29) Mills, C.F. (1961). Rowett. Res. Inst. Collect. Pap., 17, 71.

30) Huisingh, J., Gomez, G.G. and Matrone, G. (1973). Fed. Proc., 32, 1921.

31) Suttle, N.F. (1975). In Trace Elements in soil-plant-animal system. (Nicholas, D.J.D. and Egan, A.R., Eds.), p. 271, Acad. Press, New York. 